\title{
Aumento da freqüência de resistência à norfloxacina e ciprofloxacina em bactérias isoladas em uroculturas
}

\author{
A.A. Lopes, K. Salgado, R. Martinelli, H. Rocha \\ Hospital Universitário Prof. Edgard Santos, Universidade Federal da Bahia, Salvador, BA
}

\begin{abstract}
RESUMO - Овј etivo. Avaliar mudanças, ao longo dos anos, na freqüência de resistência à norfloxacina e ciprofloxacina em bactérias isoladas de uroculturas.

Métodos. Resultados de todas as uroculturas com crescimento bacteriano de pelo menos $10^{5}$ unidades formadoras de colônias por $\mathrm{mL}$ de urina (UFC/mL), realizadas no Serviço de Nefrologia da Universidade Federal da Bahia durante o período 1983-1994, foram analisadas. As bactérias incluídas na análise foram aquelas mais freqüentemente isolados: Escherichia coli $(n=668)$, Klebsiella spp. $(n=286)$, Staphylococcus spp. $(n=186)$, Proteus spp. $(n=135)$ e Enterobacter spp. $(n=129)$.

Resultados. A freqüência de bactérias resistentes à norfloxacina foi de $3,2 \%$, no período 1983-1986; 5,9\%, no período $1987-1990$; e 9,1\%, no período 1991-1994 (p<0,05). Klebsiella spp. e Enterobacter spp. foram as bactérias que apre-
\end{abstract}

\section{NTRODUÇÃO}

As bactérias resistentes à múltiplos antimicrobianos representam um desafio no tratamento de infecções ${ }^{1}$. A introdução de fluoroquinolonas, grupo ao qual pertencem a norfloxacina e ciprofloxacina, na década de 80 , significou, sem dúvida, um avanço no tratamento de infecções por bactérias multirresistentes, particularmente infecções do trato urinário (ITU $)^{2-4}$, visto que diversas cepas de bactérias resistentes a múltiplos antimicrobianos mostraram-se sensíveis a esse novo grupo de medicamentos ${ }^{5,6}$. Trabal hos mais recentes, no entanto, têm alertado para um aumento da freqüência de bactérias resistentes às quinolonas ${ }^{7-10}$. Esse problema tem sido observado principalmente em pacientes com septicemias graves causadas por bactérias provenientes do trato urinário ${ }^{8-10}$. O presente estudo foi realizado com o objetivo bási co de avaliar possíveis modificações, ao longo dos anos, na sensibilidade à norfloxacina e ciprofloxacina de bactérias isoladas de uroculturas provenientes de pacientes ambulatoriais e hospitalizados de um Hospital Universitário localizado em Salvador, BA. sentaram maiores aumentos na freqüência de resistência à norfloxacina. Para a ciprofloxacina, constatou-se resistência em $7,4 \%$ das bactérias isoladas, no período $1985-1989$, e $16,5 \%$, no período 1990-1994 $(p<0,05)$. Esse aumento na freqüência de bactérias resistentes à ciprofloxacina foi mais marcante para Enterobacter spp. e Staphylococcus spp.

Conclusões. Os resultados do presente estudo mostram um aumento gradual na freqüência de resistência à norfloxacina e ciprofloxacina entre as bactérias mais comumente isoladas em uroculturas. A influência do uso prévio de quinolonas e de peculiaridades da bactéria infectante, nesses achados, representa importante questão a ser investigada.

Unitermos: Resistência antimicrobiana. QuinoIonas. Infecção do trato urinário.

\section{MÉTODOS}

Foi feito um levantamento de todas as uroculturas positivas ( $\geq 10^{5}$ unidades formadoras de colônias por $\mathrm{mL}$ de urina, UFC/mL) para as espécies bacterianas mais freqüentemente isoladas (Escherichia coli, Klebsiella spp. Staphylococcus spp., Proteus spp. e Enterobacter spp.) no período 1983-1994 e que foram testadas para a sensibilidade à norfloxacina ou ciprofoxacina no laboratório de bacteriologia da Disciplina de N efrologia, Universidade F ederal da Bahia. Esse laboratório recebe material proveniente tanto de pacientes ambulatoriais quanto hospitalizados.

Procedimentos mi crobiológicos - $\mathrm{O}$ jato médio da urina de cada paciente foi col etado em recipientes esterilizados no próprio laboratório. Após recebimento da amostra, realizava-se a semeadura direta da urina em meios de ágar sangue e McConkey com alça de platina calibrada $(0,01 \mathrm{~mL})$, fazendo-se, no dia seguinte (18 a 24 horas), a contagem, na placa de ágar sangue, das colônias bacterianas surgi das ${ }^{11-13}$. E m adição procedeu-se, nas fases iniciais do estudo (1983-1986), a diluição (1/1.000) da urina em solução salina fisiológica estéril, seguida 


\begin{tabular}{|c|c|c|c|c|c|c|c|c|}
\hline \multirow[b]{2}{*}{ Bactéria } & \multicolumn{2}{|c|}{$1983-1986$} & \multicolumn{2}{|c|}{$1987-1990$} & \multicolumn{2}{|c|}{ 1991-1994 } & \multicolumn{2}{|c|}{ Total } \\
\hline & $\mathbf{N}$ & $\%$ & $\mathbf{N}$ & $\%$ & $\mathbf{N}$ & $\%$ & $\mathbf{N}$ & $\%$ \\
\hline E. coli & 282 & 41,5 & 197 & 52,7 & 189 & 53,8 & 668 & 47,6 \\
\hline Klebsiella spp. & 156 & 23,0 & 67 & 17,9 & 63 & 17,9 & 286 & 20,4 \\
\hline Staphylococcus spp. & 87 & 12,8 & 45 & 12,0 & 54 & 15,4 & 186 & 13,2 \\
\hline Proteus spp. & 79 & 11,6 & 37 & 9,9 & 19 & 5,4 & 135 & 9,6 \\
\hline Enterobacterspp. & 75 & 11,1 & 28 & 7,5 & 26 & 7,4 & 129 & 9,2 \\
\hline Total & 679 & & 374 & & 351 & & 1.404 & \\
\hline
\end{tabular}

da inoculação em $10 \mathrm{~mL}$ de ágar fundido e resfriado a $45^{\circ} \mathrm{C}^{13}$. Esse material era distribuído em placa de Petri estéril e incubado por 24 horas a $37^{\circ} \mathrm{C}$. O número de colônias era novamente estimado em contador de colônias tipo Quebec Spencer ${ }^{13}$. Considerando a concordância entre os dois métodos de contagem de colônias, a partir de 1987 passou-se a usar apenas a inoculação da urina com a alça de platina, ficando o método da inoculação da urina diluída restrito aos estudos experimentais. Havendo crescimento de bactérias apenas em ágar sangue, eram feitas lâminas coradas pelo Gram. Quando se observava crescimento tanto em ágar sangue e Mc Conkey e sendo detectada a presença de bactérias gram-negativas, procedia-se a identificação através das seguintes provas bioquímicas: 1) fermentação de açúcares (glicose, sacarose e lactose); 2) produção de indol em caldo peptonado; 3) degradação de uréia; 4) motilidade em meio semi-sólido; e 5) utilização do citrato.

Após identificação das bactérias, realizavam-se os antibiogramas através do método de difusão do disco em ágar de Mueller-Hinton ${ }^{11}$. Após o isolamento e identificação bacteriana, 4 a 5 colônias eram repicadas em cal do peptonado, incubadas em estufa bacteriológica por aproximadamente 6 horas e, na presença de crescimento bacteriano, evidenciado através de turvação do caldo, fazia-se comparação com uma solução padrão, baseada na escala de Mac Farland (suspensão de sulfato de bário, escala 0,5$)^{11,12}$. Os discos com antibióticos eram distribuídos na placa, de forma a manter uma distância de aproximadamente $24 \mathrm{~mm}$ entre eles. Após esses procedimentos, as placas eram incubadas por 24 horas. A determinação do grau de sensibilidade bacteriana levou em consideração o diâmetro do halo seguindo orientações do National Committee for Clinical Laboratory Standar$\mathrm{ds}^{14,15}$. Amostras de E. coli (ATCC 25922) e Stapylococcus aureus (ATCC 29213) foram usadas para o controle de qualidade, seguindo recomendações do NCCLS ${ }^{11-16}$.

\begin{tabular}{|c|c|c|c|c|}
\hline Período & Total & Resistentes & $\% *$ & $\begin{array}{l}\text { Razão de freqüência } \\
(\text { RF })^{\star \star}(\text { IC } 95 \%)^{\star \star \star *}\end{array}$ \\
\hline 1983-1986 & 679 & 22 & 3,2 & referência \\
\hline 1987-1990 & 374 & 22 & 5,9 & $1,8(1,0-3,2)$ \\
\hline 1991-1994 & 351 & 32 & 9,1 & $2,8(1,7-4,8)$ \\
\hline
\end{tabular}

*Qui-quadrado de Pearson=15,83; graus de liberdade $=2 ; p<0,001$. Quiquadrado para tendência linear em proporções $=15,77$; grau de liberdade $=1 ; p<0,0001 .{ }^{* *} \mathrm{RF}=$ freqüência de cada período dividida pela freqüência do período de referência, 1983-1986. ${ }^{* \star \star}$ IC 95\%=Intervalo de confiança de $95 \%$.

Análise dos dados - Para a norfloxacina, usouse o período 1983-1986 como base para avaliação da modificação na freqüência de resistência bacteriana. Por outro lado, para a ciprofloxacina, um antimicrobiano introduzido para o tratamento de ITU mais recentemente do que a norfloxacina, o período 1985-1989 foi usado como base para comparações. Procedimentos do software de estatística, Statistical Package for the Social Sciences, SPSS $^{17}$, foram usados para a análise dos dados. A razão de freqüência (RF) de resistência foi determinada através da divisão da freqüência de bactérias resistentes em um determinado período pela freqüência no período de base (1983-1986 para a norfloxacina e 1985-1989 para a ciprofloxacina). Portanto, uma RF igual a 1,0 significa que não houve mudança na freqüência de resistentes entre os períodos. Desvios da RF do valor 1,0 indica em quantas vezes, mai or ou menor, foi a freqüência de resistentes em um determinado período, quando comparada com o período de base. A precisão da RF foi descrita através dos intervalos de confiança de 95\% (I C 95\%). A significância estatística da associação entre resistência bacteriana e o período foi avaliada através do teste do qui-quadrado de Pearson ou do teste exato de Fischer, quando as exigências para o uso do qui-quadrado não foram preenchidas ${ }^{18}$. Para avaliar a significância estatís- 
Tabela 3 - Freqüência (\%) de resistência à norfloxacina de acordo com o período (1987-1994 vs. 1983-1986) e o tipo de bactéria

\begin{tabular}{|c|c|c|c|c|c|c|c|c|}
\hline \multirow[b]{2}{*}{ Bactéria } & \multicolumn{3}{|c|}{$\begin{array}{c}\text { 1983-1986 } \\
\text { (Período 1) }\end{array}$} & \multicolumn{3}{|c|}{$\begin{array}{c}\text { 1987-1994 } \\
\text { (Período 2) }\end{array}$} & \multirow{2}{*}{$\begin{array}{c}\text { Razão de freqüência } \\
\text { (RF) } \\
(\text { IC 95\%) }\end{array}$} & \multirow{2}{*}{$\begin{array}{c}\text { Significância } \\
\text { estatística }\end{array}$} \\
\hline & Total & Resistentes & $\%$ & Total & Resistentes & $\%$ & & \\
\hline E. coli & 282 & 2 & 0,7 & 386 & 5 & 1,3 & $1,8(0,4-9,4)$ & $N S^{* * *}$ \\
\hline Klebsiella spp. & 156 & 4 & 2,6 & 130 & 19 & 14,6 & $5,7(2,0-16,3)$ & $p<0,01$ \\
\hline Staphylococcus spp. & 87 & 13 & 14,9 & 99 & 23 & 23,2 & $1,6(0,8-2,9)$ & NS \\
\hline Proteus spp. & 79 & 1 & 1,3 & 56 & 1 & 1,8 & $1,4(0,1-22,1)$ & NS \\
\hline Enterobacter spp. & 75 & 2 & 2,7 & 54 & 6 & 11,1 & $4,2(0,8-2,9)$ & $0,05<p<0,1$ \\
\hline Total & 679 & 22 & 3,2 & 725 & 54 & 7,4 & $2,3(1,4-3,70)$ & $p<0,01$ \\
\hline
\end{tabular}

Tabela 4 - Freqüência (\%) de resistência à ciprofloxacina de acordo com o período (1990-1994 vs. 1985-1989) e o tipo de bactéria

\begin{tabular}{|c|c|c|c|c|c|c|c|c|}
\hline \multirow[b]{2}{*}{ Bactéria } & \multicolumn{3}{|c|}{$\begin{array}{c}\text { 1985-1989 } \\
\text { (Período 1) }\end{array}$} & \multicolumn{3}{|c|}{$\begin{array}{c}\text { 1990-1994 } \\
\text { (Período 2) }\end{array}$} & \multirow{2}{*}{$\begin{array}{c}\text { Razão de frqüência } \\
\text { (RF) } \\
(\text { IC } 95 \%)^{\star *}\end{array}$} & \multirow{2}{*}{$\begin{array}{c}\text { Significância } \\
\text { estatística }\end{array}$} \\
\hline & Total & Resistentes & $\%$ & Total & Resistentes & $\%$ & & \\
\hline E. coli & 218 & 9 & 4,1 & 159 & 5 & 3,1 & $0,8(0,3-2,2)$ & $\mathrm{NS}^{* * *}$ \\
\hline Klebsiella spp. & 88 & 9 & 10,2 & 61 & 12 & 19,7 & $1,9(0,9-4,3)$ & NS \\
\hline Staphylococcus spp. & 46 & 11 & 23,9 & 55 & 30 & 54,5 & $2,3(1,3-4,0)$ & $p<0,01$ \\
\hline Proteus spp. & 50 & 2 & 4 & 17 & 0 & - & - NS & \\
\hline Enterobacterspp. & 44 & 2 & 4,5 & 18 & 4 & 22,2 & $4,9(1,0-24,4)$ & $0,05<p<0,1$ \\
\hline Total & 446 & 33 & 7,4 & 310 & 51 & 16,5 & $2,2(1,5-3,4)$ & $p<0,01$ \\
\hline
\end{tabular}

tica na modificação da resistência à norfloxacina ao longo de três períodos, foi também utilizado o teste do qui-quadrado para tendência linear em proporções (extensão de Mantel-Haenszel) ${ }^{19}$. U ma probabilidade de erro tipo I, "bicaudal", menor do que 0,05 , foi considerada estatisticamente significante; quando a probabilidade do erro tipo 1 ficou entre 0,05 e 0,1, a associação entre resistência bacteriana e período foi considerada moderadamente significante.

\section{RESULTADOS}

No período 1983-1994 (tabela 1), Escherichia coli, Klebsiella spp. Staphylococcus spp., Proteus spp. e Enterobacter spp. foram, nessa ordem, as espécies bacterianas mais freqüentemente isoladas em uroculturas. Um pequeno predomínio na freqüência de Enterobacter spp. $(7,4 \%)$ relativa à freqüência de Proteus spp. $(5,4 \%)$ foi, no entanto, observado no período 1991-1994.

Houve um aumento estatisticamente significante $(p<0,001)$ na freqüência de bactérias resistentes à norfloxacina ao longo dos anos (tabela 2). No período 1983-1986, a freqüência de resistentes foi de 3,2\%. Comparativamente a esse período inicial, ocorreu um aumento de 1,8 (5,9\%/3,2\%) vez no percentual de bactérias resistentes, no período $1987-1990$, e de $2,8(9,1 \% / 3,2 \%)$ vezes no período 1991-1994.

A tabela 3 compara as freqüências de bactérias resistentes à norfloxacina no período 1987-1994 com o período 1983-1986. A freqüência de resistentes foi 2,3 vezes maior $(p<0,01)$ no período 1987 1994 (7,4\%), quando comparada com aquela do período 1983-1986 (3,2\%). E sse aumento no encontro de bactérias resistentes foi observado para cada uma das espéci es estudadas; no entanto, para Escherichia coli, Proteus spp. e Staphylococcus spp., os val ores da RF não al cançaram significância estatística $(p>0,1)$. Klebsiella spp. foi a bactéria que apresentou o aumento mais acentuado no surgimento de cepas resistentes ( $R F=5,7$; IC $95 \%=2,0-16,3 ; p<0,01)$ entre os dois períodos. Enterobacter spp. ocupou a segunda posição, embora a RF $(4,2)$ tenha sido apenas moderadamente significante $(0,05<p<0,1)$.

As freqüências de resistência à ciprofoxacina por intervalos de cinco anos são mostradas na tabela 4. Bactérias resistentes a esse antimicrobiano, no período 1990-1994 (16,5\%), foi 2,2 vezes maior $(p<0,01)$ do que no período 1985-1989 $(7,4 \%)$. No entanto, diferente do que foi descrito para a norfloxacina, não houve uniformidade na 
direção da modificação da resistência à ciprofloxacina nas comparações específicas para cada espécie bacteriana.

Klebsiella spp., Enterobacter spp. e Staphylococcus spp. foram as bactérias que apresentaram mai or aumento da resistência à ciprofloxacina ao longo dos anos (tabela 4). Ao comparar-se o período 1990-1994 com o período 1985-1989, observou-se um aumento de resistência de aproximadamente duas vezes para a Klebsiel la spp. e Staphyl ococcus spp. $(p<0,05)$ e de aproximadamente cinco vezes para o Enterobacter spp.; no entanto, a RF não alcançou significância estatística $(p>0,1)$ para a Klebsiella spp., e foi moderadamente significante $(0,05>p>0,1)$ para o Enterobacter spp. É importante observar que não se constatou aumento da resistência à ciprofloxacina para a Escherichia coli e Proteus spp.

\section{DISCUSSÃO}

Os resultados deste estudo chamam atenção para um aumento da resistência à norfloxacina e ciprofloxacina, ao longo dos anos, entre as bactérias mais freqüentemente isoladas em uroculturas. No entanto, o padrão da modificação da resistência bacteriana não foi uniforme entre os diferentes tipos de bactérias.

O rápido aumento da freqüência de Klebsiella spp. resistente à norfloxacina é um dado preocupante, principalmente se for considerado que esse agente infectante é um dos mais freqüentemente isolados em paci entes com ITU. As modificações na resistência da Klebsiella spp. e do Proteus spp. foram muito mais acentuadas para a norfloxacina do que para a ciprofloxacina. Embora o número pequeno de casos seja insuficiente para uma conclusão segura, é interessante observar a ausência de casos de Proteus spp. resistente à norfloxacina no período 1990-1994.

Escherichia coli apresentou uma das freqüências mais baixas de resistência bacteriana e pequena modificação na sensibilidade à norfloxacina e ciprofloxacina, nos períodos estudados. Esse dado pode ser visto como animador, principalmente ao se levar em consi der ação que E scherichia coli é ainda a bactéria mais freqüentemente isol ada em pacientes com ITU. No entanto, diversos investigadores têm chamado atenção para o crescimento lento da resistência da Escherichia coli à norfloxacina, ciprofloxacina e outras quinol onas, o que parece estar, em parte, relacionado ao uso freqüente desses antimicrobianos na profilaxia de infecções e na terapia de ITU ${ }^{20}$.
A freqüência el evada de Staphylococcus spp. resistentes à norfloxacina e ciprofloxacina, desde a época em que foram introduzidas, é consistente com o que tem sido descrito em diversos tipos de infecção ${ }^{21,22}$, incluindo ITU ${ }^{23,24}$. É importante observar que existem indicações que essas cepas de Staphyl ococcus resistentes à norfloxacina e ciprofloxacina são mais freqüentemente resistentes a diversos outros antimicrobianos ${ }^{21}$.

Não foi possível avaliar, diretamente, os fatores que influenciaram o aumento da resistência das bactérias estudadas às quinol onas. No entanto, os dados existentes na literatura sugerem que o uso prévio de quinol onas exerce um importante papel no crescimento de bactérias resistentes a esses antimicrobianos ${ }^{25}$. O papel do uso prévio de quinolônicos e de certas peculiaridades da bactéria infectante no aumento da resistência à norfloxacina e ciprofloxacina deve ser visto como uma importante questão para ser explorada em pesquisas futuras.

\section{SUMMARY}

\section{Increase in the frequency of norfloxacin and ciprofloxacin resistance of bacteria isolated from urine culture}

Oвjective. To assess time trends in the frequency of norfloxacin and ciprofloxacin resistance of bacteria isolated from urine culture.

Methods. Results of all urine cultures with a bacterial growth of at least $10^{5}$ colony-forming units per milliter, performed at the Renal Service of the Federal University of Bahia, Brazil, from 1983 to 1994 were analyzed. The bacteria considered for this analysis were those most often isolated: Escherichia coli $(n=668)$, Klebsiella spp. $(n=286)$, Staphylococcus spp. $(n=186)$, Proteus spp. $(n=135)$ and Enterobacter spp. $(n=129)$.

RESULTS. The frequencies of norfloxacin resistance for the periods 1983-1986, 1987-1990 and 1991-1994 were 3.2\%, 5.9\% and 9.1\%, respectively ( $p$-value $<0.05$ ). The most pronounced increases in the frequencies of norfloxacin-resistance were observed for K lebsiella spp. and E nterobacter spp. The frequency of ciprofloxacin resistance was $7.4 \%$ in the period $1985-1989$ and $16.5 \%$ in the period 1990-1994 ( $p$-value<0.05). This time trend in ciprofl oxacin resistance was more striking for Enterobacter spp. and Staphylococcus spp.

ConCLUSION. The results show a gradual increase in the frequency of norfloxacin and ciprofloxacin resistance of the bacteria most commonly isolated from urine cultures. The influence of 
previous treatment with quinolones and characteristics of the infecting bacteria on these findings are important questions to to be addressed in future investigations. [Rev Ass Med Brasil 1998; 44(3): 196-200.]

KEY WORDS: Antimicrobial resistance. Quinolone. Urinary tract infection.

\section{REFERÊNCIAS BIBLIOGRÁFICAS}

1. Murray BE. New aspects of antimicrobial resistance and the resulting therapeutic dilemmas. J I nfect Dis 1991; 163: 1.18594.

2. Ryan J L, Berenson CS, Greco TP et al. Mangi RJ , Sims M, Thornton GF, Andriole VT. Oral ciprofloxacin in resistant urinary tract infections. Am J Med 1987; 82: 303-6.

3. Tolkoff NE, Rubin RH. New approaches to the treatment of urinary tract infection. Am J Med 1987; 82: 270-7.

4. Daikos GL, Kathpalia SB, Sharifi R, Lolans VT, J ackson GG. Comparison of ciprofloxacin and beta-lactam antibiotics in the treatment of urinary tract infections and alteration of fecal flora. AmJ Med 1987; 82: 290-4.

5. Neu HC. Ciprofloxacin: an overview and prospective appraisal. AmJ Med 1987; 82: 395-404.

6. Neu HC. Quinol ones: a new class of antimicrobial agents with wide potential uses. Med Clin North Am 1988; 72: 623-36.

7. Hooper DC, Wolfson J S. Bacterial resistance to the quinol one antimicrobial agents. Am J Med 1989; 87: 17S-23S.

8. Carratala J , Fernandez-Sevilla A, Tubau F, Callis M, Gudiol $F$. Emergence of quinolone-resistant Escherichia coli bacteremia in neutropenic patients with cancer who have received prophylactic norfloxacin. Clin I nfect Dis 1995; 20: 557-60.

9. Pena C, Albareda J M, Pallares R et al. Relationship between quinolone use and emergence of ciprofloxacin-resistant Escherichia coli in bloodstream infections. Antimicrob Agents Chemother 1995; 39: 520-4.

10. Cometta A, Calandra T, BilleJ , Glauser MP. Escherichia coli resistant to fluoroquinolones in patients with cancer and neutropenia. New Engl J Med 1994; 330: 1.240-1.

11. Finegold SM, Martin WJ . Diagnósti co microbiológi co. Editora Médica Panamericana, São Paulo, SP, 1983.
12. Bier O. Microbiologia eimunologia. Editora Mel horamentos, São Paulo, SP, 1984.

13. Huvos $A$, Rocha $H$. Frequency of bacteriuria in patients with diabetes mellitus: a controlled study. New Eng J Med 1959; 261: 1.213-6.

14. National Committee for Clinical Laboratory Standards. Performance standards for antimicrobial disk susceptibility tests: approved standards. NCCLS 1979; document no. ASM-2.

15. National Committee for Clinical Laboratory Standards. Performance standards for antimicrobial disk susceptibility tests. Villanova, Pa: NCCLS 1984; document no. M2-A3.

16. NCCLS Subcommittee on Antimicrobial Susceptibility Testing. Standard methods for dilution antimicrobial susceptibility tests for bacteria which grow aerobically. Proposed standards. NCCLS 1990; document PSM-7.

17. Norušis MJ . SPSS for Windows: Base System User's Guide, release 6.0, SPPS Inc, Chicago, IL, 1993.

18. Fleiss J L. Statistical methods for rates and proportions, $2^{\text {nd }}$ edition. J ohn Wiley \& Sons, New York, NY, 1981.

19. Schlesselman. Case-control studies. New York, Oxford Univ. Press, 1982; 203-6.

20. Richard P, Delangle MH, Merrien D et al. Fluoroquinol one use and fluoroquinol one resistance: is there an association? Clin Infect Dis 1994; 19: 54-9.

21. Blumberg HM, Rimland D, Carrolli DJ , Terry P, Wachsmuth K. Rapid development of ciprofloxacin resistance in methicillin-susceptible and resistant Staphylococcus aureus. J Infect Dis 1991; 163: 1.279-85.

22. Teixeira LA, Resende CA, Ormonde LR et al. Geographic spread of epidemic multiresistant Staphylococcus aureus clone in Brazil. J Clin Microbiol 1995; 33: 2.400-4.

23. Waites K, Rand K, J enkins S et al. Multicenter in vitro comparativestudy of fluoroquinol ones after four years of widespread clinical use. Diagn Microbiol I nfect Dis 1994; 18: 181-9.

24. Coronado VG, Edwards J R, Culver DH, Gaynes RP. Ciprofloxacin resistance among nosocomial Pseudomonas aeruginosa and Staphylococcus aureus in the United States. National Nosocomial Infections Surveillance (NNIS) System. I nfect Control Hosp Epidemiol 1995; 16: 71-5.

25. Muder RR, Brennen C, Goetz AM, Wagener MM, Rihs J D. Association with prior fluoroquinol one therapy of widespread ciprofloxacin resistance among gram-negative isolates in a Veterans Affairs medical center. Antimi crob Agents Chemother 1991; 35: 256-8. 